\title{
Optimal Pricing and Ordering Policies for Inventory System with Two-Level Trade Credits Under Price-Sensitive Trended Demand
}

\author{
Nita H. Shah • Dushyantkumar G. Patel • \\ Digeshkumar B. Shah
}

Published online: 24 September 2014

(C) Springer India Pvt. Ltd. 2014

\begin{abstract}
In this paper, an inventory system is depicted for trended demand. Here, the demand is assumed to be price-sensitive and time dependent. Our goal is to maximize the profit of the retailer. Here, the supplier offers a fixed credit period to the retailer and the retailer also offers credit period to the customers which is more practical scenario in the market. Sensitivity analysis is performed to determine critical inventory parameters. The proposed inventory model is validated by a numerical example.
\end{abstract}

Keywords EOQ Price-sensitive trended demand - Two level trade credits

\section{Introduction}

In the traditional model, it is assumed that the retailer should pay for items as soon as the items are received. To offer credit period is considered to be an effective promotional tool for increasing profit for both the players. By offering credit period without interest sales is promoted in the age of competition. Goyal [7] studied the EOQ model by allowing permissible delay in payment. Aggarwal and Jaggi [1] developed mathematical model for deteriorating inventories for which supplier allowed certain fixed period to settle the account. Jamal et al. [12] extended the above model by allowing shortages. Shah et al. [19] prepared a review on trade credits and inventory modeling. Sarker et al. [16] developed supply chain model

N. H. Shah $(\varangle)$

Department of Mathematics, Gujarat University, Ahmedabad 380009, Gujarat, India e-mail: nitahshah@gmail.com

D. G. Patel

Department of Mathematics, Govt. Polytechnic for Girls, Ahmedabad 380015, Gujarat, India e-mail: dushyantpatel_1981@yahoo.co.in

D. B. Shah

Department of Mathematics, L. D. College of Engg, Ahmedabad 380015, Gujarat, India e-mail: digeshshah2003@yahoo.co.in 
for deteriorating items incorporating inflation and permissible delay in payment. Chang [2] discussed an EOQ model for deteriorating items considering inflation and credits linked to order quantity. Chung and Huang [5] developed an EPQ inventory model to obtain optimal cycle time under permissible delay in payment. Teng et al. [23] derived model of optimal pricing and ordering policies with permissible delay in payment. Liao [13] developed an EPQ model incorporating effect of deterioration of items and delayed payment. Teng et al. [20] constructed a review on inventory lot-size models with trade credits.

In earlier articles, the credit period was offered by supplier to the retailer only. But the retailer was not giving credit period to customers. Huang [8] developed an inventory model in which the supplier offers the retailer a credit period $M$ and the retailer passes a credit period $N$ to his customers; with $N<M$. This phenomenon is known as two-level trade credits financing. Huang $[9,10]$ added the ideas of limited storage capacity and finite production rate respectively. Teng and Chang [21] extended Huang's [10] model by skipping the dispensable assumption of $\mathrm{N}<\mathrm{M}$. Jaggi et al. [11] established an inventory model considering creditlinked demand with two levels of trade credit. Liao [14] proposed an EOQ model having non-instantaneous receipt and exponentially deteriorating items under two-level trade credit. Shah et al. [17] derived an inventory model considering trade credit linked to order quantity for deteriorating items under stock-dependent demand. Shah et al. [18] discussed an inventory model with two players in the supply chain for price sensitive trapezoidal demand with net credit scenario for deteriorating inventory. One can also refer articles related to trade credit from Chen et al. [3], Chung and Cárdenas-Barrón [4], Chung et al. [6], Ouyang et al. [15] and $\mathrm{Wu}$ et al. [24].

In this paper, we study inventory system with trended demand under two-level trade credit financing. Supplier offers credit period $M$ to retailer and retailer gives credit period $N$ to his customers. The goal is to maximize the total profit per unit time of the retailer with respect to pricing and ordering.

The paper is organized as follows. Section two is about assumptions and notations. Mathematical model is developed in section three. In section four, numerical examples and managerial issues are given. Conclusions are exhibited in section five.

\section{Notations and Assumptions}

\section{Notations}

$R(s, t) \quad$ Price-sensitive linear demand rate. The functional form is $R(s, t)=a(1+b t) s^{-\eta}$ where $a>0$ is known and constant scale demand; $0<b<1$ is the rate at which demand is increasing linearly with time; $s$ is retail price and $\eta>1$ is price mark up

A Ordering cost per order

C Unit purchase cost

$s \quad$ Unit retail price (a decision variable) where $s>C$

$h \quad$ Inventory holding cost (excluding interest charges) per unit per unit time

$I_{e} \quad$ Interest earned per $\$$ per year

$I_{c} \quad$ Interest charged per $\$$ for unsold items per year by the supplier

$M \quad$ Credit period (in years) offered by the supplier to the retailer

$N \quad$ Credit period (in years) offered by the retailer to the customer

$I(t) \quad$ Inventory level at any instant of time $\mathrm{t}, 0 \leq t \leq T$

$T \quad$ Cycle time (a decision variable) 
$Q \quad$ Purchase quantity per cycle (a decision variable)

$\pi(s, T) \quad$ Retailer's total profit per unit time

Assumptions

1. Single item inventory system is considered.

2. The planning horizon is infinite.

3. Shortages are not allowed. Lead-time is zero or negligible.

4. The demand rate $R(s, t)$ is function of time and the retail price of the retailer, (say)

$$
R(s, t)=a(1+b t) s^{-\eta}
$$

where $a>0,0<b<1$ and $\eta>1$.

5. The offer of credit period $N$ to the customers by the retailer results inflow of revenue in $[N, T+N]$ for the retailer. This assumption is also taken by Teng and Goyal [22].

6. When $M \leq T+N$, the account is to be settled at $M$ and for the unsold items, the retailer would pay interest during $[M, T+N]$ at the rate $I_{c}$. When $M>T+N$, the retailer will settle the account at $M$ and does not pay any interest charges during the cycle.

7. The retailer generates revenue by selling items and earns interest during $[N, M]$ with rate $I_{e}$.

\section{Mathematical Model}

The inventory level at any instant of time $t$ is governed by the differential equation

$$
\frac{d I(t)}{d t}=-R(s, t), \quad 0 \leq t \leq T
$$

with the boundary conditioned $I(T)=0$. The solution of Eq. (2) is

$$
I(t)=a s^{-\eta}\left[T-t+\frac{b}{2}\left(T^{2}-t^{2}\right)\right]
$$

Using $I(0)=Q$, the retailer's purchase quantity per cycle is

$$
Q=I(0)=a s^{-\eta} T\left[1+\frac{b T}{2}\right]
$$

The sales revenue is

$$
S R=s \int_{0}^{T} R(s, t) d t=s^{-\eta+1} a T\left[1+\frac{b T}{2}\right]
$$

The ordering cost is

$$
O C=A
$$

The purchase cost of $Q$-units is

$$
P C=C Q=\operatorname{Cas}^{-\eta} T\left[1+\frac{b T}{2}\right]
$$


The holding cost is

$$
H C=h a s^{-\eta} T^{2}\left[\frac{1}{2}+\frac{b T}{3}\right]
$$

For interest charges and earned, the following two cases are discussed depending on the duration of $M$ and $N$.

(A) Suppose $M \geq N$

Case $1 M \geq T+N$

Since $M \geq T+N$ the retailer has no unsold items in the inventory system, so the interest charges in the cycle is zero i.e. $I C_{1}=0$. The retailer generates revenue from the beginning of the cycle and settles the account at time $N$. So the retailer can earn interest at the rate $I_{e}$ per dollar per year starting from $N$ through $M$. Therefore, the interest earned per cycle is

$$
\begin{aligned}
I E_{1} & =s I_{e}\left[\int_{0}^{T} \int_{0}^{t} R(s, u) d u d t+(M-T-N) \int_{0}^{T} R(s, t) d t\right] \\
& =a s^{-\eta+1} I_{e} T\left[(M-N)\left(1+\frac{b T}{2}\right)-\frac{T}{2}-\frac{b T^{2}}{3}\right]
\end{aligned}
$$

Case $2 M \leq T+N$

In this case, the retailer does not have sufficient fund to settle the account at $M$ because customer will be paying at time $T+N$. So the retailer will have to pay interest charges during $[M, T+N]$ for unsold items at an interest rate $I_{c}$ per dollar per year. Hence, the interest charges to be paid in each cycle is

$$
\begin{aligned}
I C_{2} & =C I_{c} \int_{M}^{T+N} I(t-N) d t=C I_{c} \int_{M-N}^{T} I(t) d t \\
& =C I_{c} a s^{-\eta}\left[\frac{T^{2}}{2}+\frac{b T^{3}}{3}-T(M-N)+\frac{1}{2}(M-N)^{2}-\frac{b}{2}\left(T^{2}(M-N)-\frac{(M-N)^{3}}{3}\right)\right]
\end{aligned}
$$

Here, the retailer earns interest on the generated revenue during $[N, M]$, which is given by

$$
\begin{aligned}
I E_{2} & =s I_{e} \int_{N}^{M} \int_{N}^{t+N} R(s, u-N) d u d t=s I_{e} \int_{0}^{M-N} \int_{0}^{t} R(s, u) d u d t \\
& =s^{-\eta+1} a I_{e}\left[T^{2}\left(\frac{b T}{6}+\frac{1}{2}\right)+\frac{b}{2}\left(M^{2}-N^{2}\right)+M-N-b M N\right]
\end{aligned}
$$

Hence, the average profit per unit time for retailer is

$$
\pi(s, T)= \begin{cases}\pi_{1}(s, T), & 0 \leq T \leq M-N \\ \pi_{2}(s, T), & T \geq M-N\end{cases}
$$

where

$$
\pi_{1}(s, T)=\frac{1}{T}\left\{S R-P C-O C-H C-I C_{1}+I E_{1}\right\}
$$


and

$$
\pi_{2}(s, T)=\frac{1}{T}\left\{S R-P C-O C-H C-I C_{2}+I E_{2}\right\}
$$

(B) Suppose $M \leq N$

Here, the retailer does not earn any interest i.e. $I E_{3}=0$.

The interest is to be paid for all the items. Hence, the interest charged per cycle is

$$
\begin{aligned}
I C_{3} & =C I_{c}\left[(N-M) Q+\int_{N}^{T+N} I(t-N) d t\right] \\
& =C I_{C}\left[(N-M) Q+\int_{0}^{T} I(t) d t\right] \\
& =C s^{-\eta} a I_{c} T\left[(N-M)\left(1+\frac{b T}{2}\right)+\frac{b T^{2}}{3}+\frac{T}{2}\right]
\end{aligned}
$$

The average profit per unit time is

$$
\pi_{3}(s, T)=\frac{1}{T}\left\{S R-P C-O C-H C-P T I-I C_{3}+I E_{3}\right\}
$$

The objective is to maximize the average profit per unit time $\pi_{i}(s, T), i=1,2,3$ with respect to retail price and cycle time. The highly non-linearity of the objective functions in Eqs. (6-8) renders to obtain the closed form solution. We analyze the model with parametric data in the next section.

\section{Numerical Examples}

Differentiate $\pi_{i}(s, T), i=1,2,3$ with respect to $s$ and $T$ and equate with zero. Now follow the steps given below.

Step 1: Assign values to all inventory parameters.

Step 2: For $M \geq N$, solve simultaneously $\frac{\partial \pi_{1}}{\partial s}=0$ and $\frac{\partial \pi_{1}}{\partial T}=0$ and also $\frac{\partial \pi_{2}}{\partial s}=0$ and $\frac{\partial \pi_{2}}{\partial T}=0$.

If $M \geq T+N$ then compute $\pi_{1}$ from Eq. (6) else $\pi_{2}$ from Eq. (7). After having $(s, T)$, the retailers purchase quantity can be obtained using Eq. (4).

Step 3: For $M<N$, solve $\frac{\partial \pi_{3}}{\partial s}=0$ and $\frac{\partial \pi_{3}}{\partial T}=0$ simultaneously and find the average profit per unit time $\pi_{3}$ from Eq. (8) and purchase quantity using Eq. (4).

We study two numerical examples to demonstrate the models for $M \geq N$ and $M<N$ respectively.

Example 1 Given $A=\$ 50$ per order, $C=\$ 6$ per unit, $h=\$ 2.5 /$ unit/year, $a=10^{4}$ units, $b=10 \%, \eta=1.2, I_{e}=10 \% / \$ /$ year, $I_{c}=15 \% / \$ /$ year, $M=0.8$ year and $N=0.6$ year.

In this case, $\pi_{1}$ is $\$ 3,963.43$ at $\left(T=T_{1}=0.492, s=s_{1}=\$ 39.91\right)$ while $\pi_{2}$ is $\$ 4,294.15$ at $\left(T=T_{2}=0.455, s=s_{2}=\$ 37.36\right)$. 


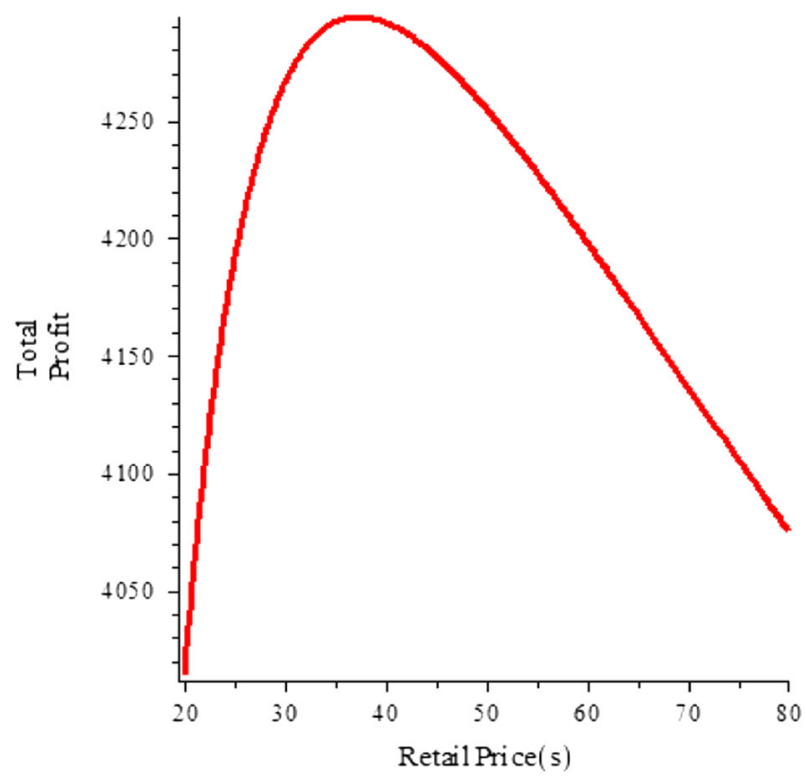

Fig. 1 Concavity of total profit w. r. t. $s$ for $M<T+N$ for obtained $T$

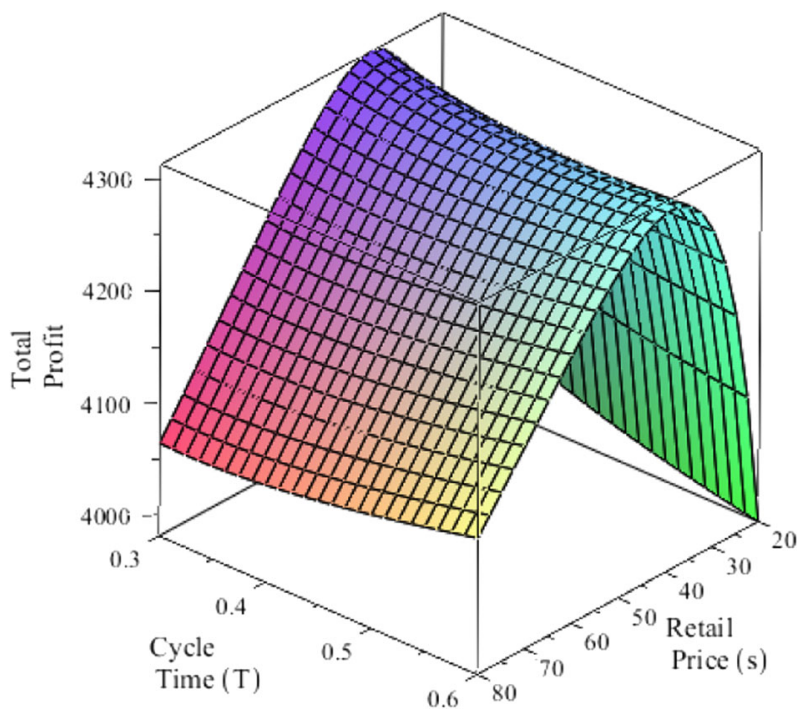

Fig. 2 Concavity of total profit for cycle time $T$ and retail price $s$

Therefore, the maximum profit for the retailer is for purchasing units $Q^{*}=60.43$ units during cycle is $\pi^{*}\left(=\pi_{2}^{*}\right)=\$ 4,294.15$. The concavity of the average total profit per unit time is shown in Fig. 1 w. r. t. retail price $s$ for obtained $T=0.455$ years. 3-D plot of the average total profit per unit time shows concavity w. r. t. selling price and replenishment time in Fig. 2. 


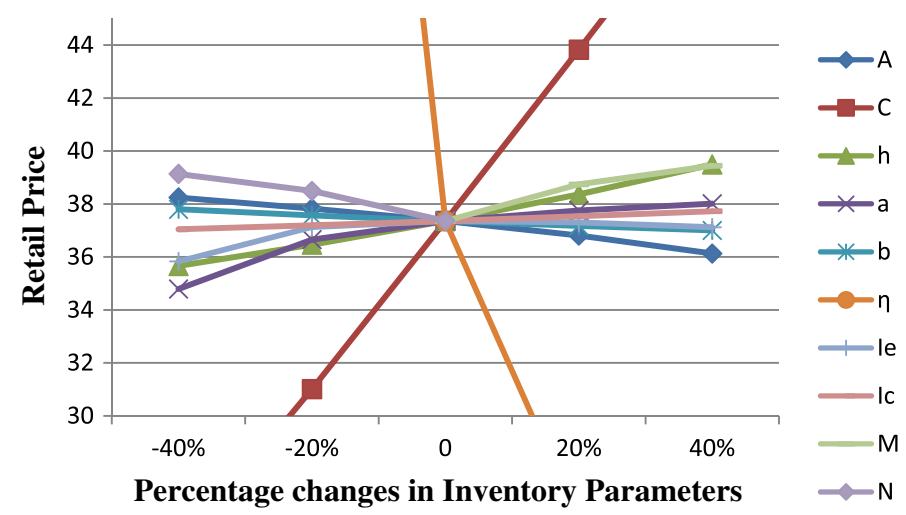

Fig. 3 Sensitivity analysis for retail price $(s)$

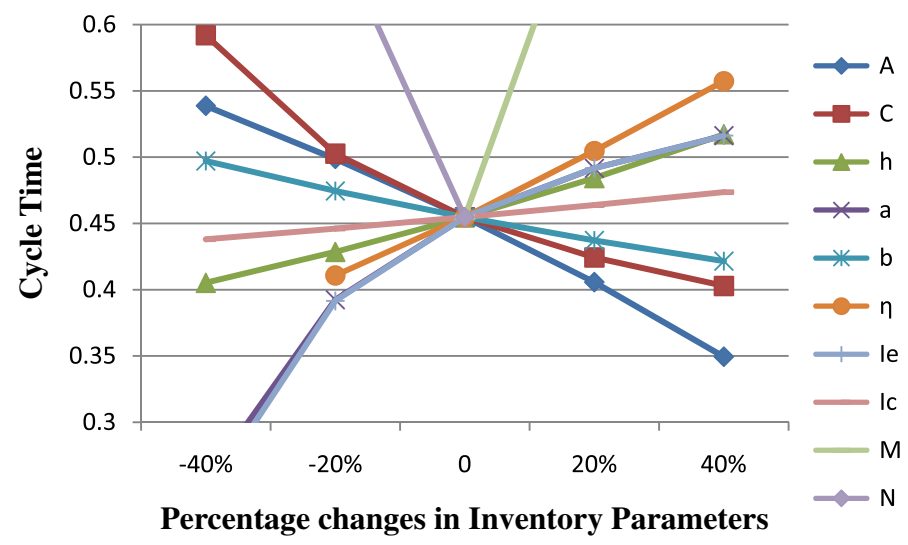

Fig. 4 Sensitivity analysis for cycle time $(T)$

Example 2 Take $A=\$ 40$ per order, $C=\$ 3$ per unit, $h=\$ 1 /$ unit/year, $a=10^{4}$ units, $b=1 \%, \eta=2.2, I_{e}=15 \% / \$ /$ year, $I_{c}=10 \% / \$ /$ year, $M=0.6$ year and $N=0.8$ year.

We have $M<N$. Then from step 3 of the procedure above, we get $\pi_{3}$ is $\$ 418.72$ at $\left(T=T_{3}=0.565, s=s_{3}=\$ 6.28\right)$.

Now we are interested to study how variations in inventory parameters affect decision variables and profit function. For that we perform sensitivity analysis. We vary the parameters given in example 1 by $-40,-20,20$ and $40 \%$. The effects of variations in retail price, cycle time, order quantity and profit are shown in Figs. 3, 4, 5, and 6. The following observations are derived for the decision maker.

\section{Observations}

It is observed from Fig. 3 that selling price decreases drastically w. r. t. price mark up $\eta$ and increases significantly w. r. t purchase $\operatorname{cost} C$, scale demand $a$, the credit period $M$ offered by the supplier to the retailer and interest earned by the retailer on the generated revenue. The remaining inventory parameters have negligible impact on retail price. This suggests that by offering credit period retailer can increase demand. 


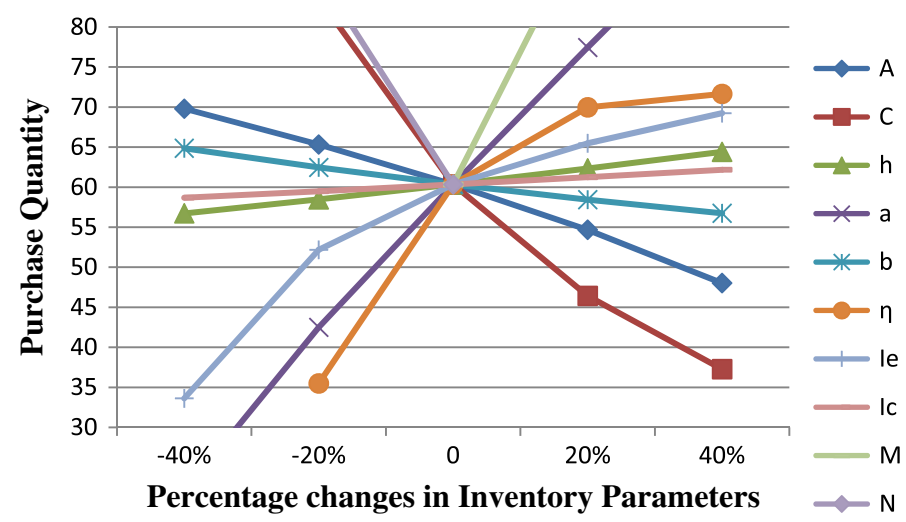

Fig. 5 Sensitivity analysis for purchase quantity $(Q)$

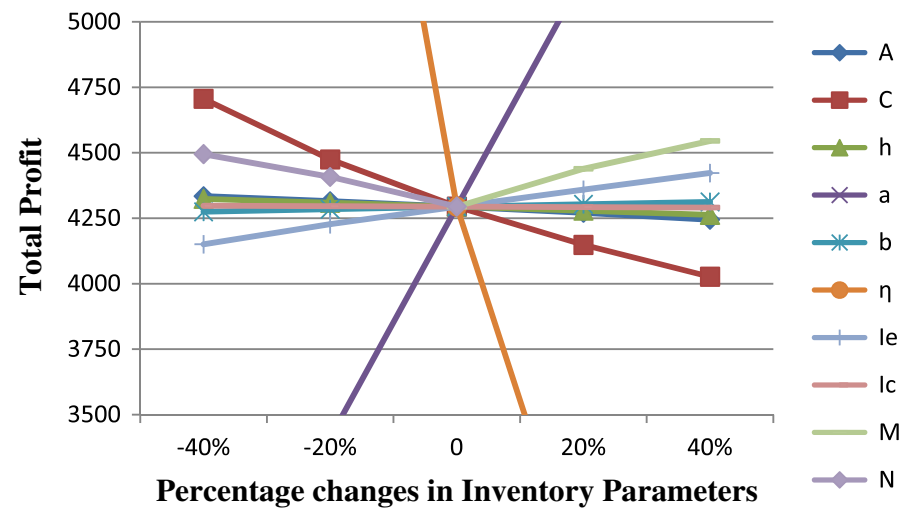

Fig. 6 Sensitivity analysis for total average profit per unit time $(\pi)$

It is observed from Fig. 4 that cycle time is decreasing significantly for ordering cost, purchase cost, delay period $N$ offered by the retailer to the customer. It increases sharply for scale demand $a$, price mark-up, the delay period $M$ offered by the supplier to the retailer, interest earned. This suggests that retailer should put order frequently when the delay period $M$ is offered by the supplier to the retailer.

It is observed from Fig. 5 that the purchase quantity increases when delay period, scale demand $a$, price mark-up $\eta$ and interest earned $I_{e}$ increases while decreases when purchase $\operatorname{cost} C$, ordering cost $A$ and $N$ decreases. This suggests that by purchasing more quantity the retailer get more interest and delay period to settle the account.

It is observed from Fig. 6 that the average total profit per unit time increases sharply with increase in $a$, and increases moderately with increase in $b, I_{e}$ and credit period offered by the supplier to the retailer $M$ and decreases significantly w. r. t. increase in $A, C, N, \eta$. This suggests that the retailer can save in ordering cost by ordering more items and giving smaller delay period to the customers. 


\section{Conclusions}

In this article, an inventory model is derived to decide the optimal pricing and ordering policies which maximizes total profit per unit time of the retailer. The demand is price-sensitive time dependent increasing. The decision policies and managerial comments are displayed from numerical examples. It is recommended that the retailer should take advantage of delay period by putting smaller orders frequently and some credit should be passed on to his customers. This benefits retailer by getting account settled earlier and reducing risk of default from customer end.

Further research can be made to study inventory models with stochastic demand, stochastic deterioration rate or both. One can also take into consideration different preservation technologies to control deterioration of items in the inventory system. One can add risk analysis to make problem more applicable.

Acknowledgments The authors are thankful to all the reviewers for their constructive suggestions.

\section{References}

1. Aggarwal, S.P., Jaggi, C.K.: Ordering policies of deteriorating items under permissible delay in payments. J. Oper. Res. Soc. 46(5), 658-662 (1995)

2. Chang, C.T.: An EOQ model with deteriorating items under inflation when supplier credits linked to order quantity. Int. J. Prod. Econ. 88(3), 307-316 (2004)

3. Chen, S.H., Cárdenas-Barrón, L.E., Teng, J.T.: Retailer's economic order quantity when the supplier offers conditionally permissible delay in payments link to order quantity. Int. J. Prod. Econ. 155, 284-291 (2014)

4. Chung, K.J., Cárdenas-Barrón, L.E.: The simplified solution procedure for deteriorating items under stockdependent demand and two-level trade credit in the supply chain management. Appl. Math. Modell. 37(7), $4653-4660$ (2013)

5. Chung, K.J., Huang, Y.F.: The optimal cycle time for EPQ inventory model under permissible delay in payments. Int. J. Prod. Econ. 84(3), 307-318 (2003)

6. Chung, K.J., Cárdenas-Barrón, L.E., Ting, P.S.: An inventory model with non-instantaneous receipt and exponentially deteriorating items for an integrated three layer supply chain system under two levels of trade credit. Int. J. Prod. Econ. 155, 310-317 (2014)

7. Goyal, S.K.: Economic order quantity under conditions of permissible delay in payments. J. Oper. Res. Soc. 36(4), 335-338 (1985)

8. Huang, Y.F.: Optimal retailer's ordering policies in the EOQ model under trade credit financing. J. Oper. Res. Soc. 54(9), 1011-1015 (2003)

9. Huang, Y.F.: An inventory model under two levels of trade credit and limited storage space derived without derivatives. Appl. Math. Modell. 30(5), 418-436 (2006)

10. Huang, Y.F.: Optimal retailer's replenishment decisions in the EPQ model under two levels of trade credit policy. Eur. J. Oper. Res. 176(3), 1577-1591 (2007)

11. Jaggi, C.K., Goyal, S.K., Goel, S.K.: Retailer's optimal replenishment decisions with credit-linked demand under permissible delay in payments. Eur. J. Oper. Res. 190(1), 130-135 (2008)

12. Jamal, A.M.M., Sarker, B.R., Wang, S.: An ordering policy for deteriorating items with allowable shortages and permissible delay in payment. J. Oper. Res. Soc. 48(8), 826-833 (1997)

13. Liao, J.J.: An EPQ model for deteriorating items under permissible delay in payments. Appl. Math. Modell. 31(3), 393-403 (2007)

14. Liao, J.J.: An EOQ model with non instantaneous receipt and exponentially deteriorating items under two-level trade credit. Int. J. Prod. Econ. 113(2), 852-861 (2008)

15. Ouyang, L.Y., Yang, C.T., Chan, Y.L., Cárdenas-Barrón, L.E.: A comprehensive extension of the optimal replenishment decisions under two levels of trade credit policy depending on the order quantity. Appl. Math. Comput. 224(1), 268-277 (2013)

16. Sarker, B.R., Jamal, A.M.M., Wang, S.: Supply chain model for perishable products under inflation and permissible delay in payment. Comput. Oper. Res. 27(1), 59-75 (2000) 
17. Shah, N.H., Patel, D.G., Shah, D.B.: Optimal integrated inventory policy for deteriorating items with stock-dependent demand and trade credit linked to order quantity. Mex. J. Oper. Res. 2(1), 2-19 (2013a)

18. Shah, N.H., Shah, D.B., Patel, D.G.: Co-ordinated shipment, ordering and payment policies for deteriorating inventory of two players in supply chain with variable price-sensitive trapezoidal demand and net credit. Int. J. Adv. Eng. Appl. 2(2), 1-14 (2013b)

19. Shah, N.H., Soni, H.N., Jaggi, C.K.: Inventory model and trade credit: review. Control Cybern. 39(3), 867-884 (2010)

20. Teng, J.T.: Inventory lot-size models under trade credits: a review. Asia Pac. J. Oper. Res. 25(1), 89-112 (2008)

21. Teng, J.T., Chang, C.T.: Optimal manufacturer's replenishment policies in the EPQ model under two levels of credit policy. Eur. J. Oper. Res. 195(2), 358-363 (2009)

22. Teng, J.T., Goyal, S.K.: Optimal ordering policies for a retailer in a supply chain with up-stream and down-stream trade credits. J. Oper. Res. Soc. 58(9), 1252-1255 (2007)

23. Teng, J.T., Chang, C.T., Goyal, S.K.: Optimal pricing and ordering policy under permissible delay in payments. Int. J. Prod. Econ. 97(2), 121-129 (2005)

24. Wu, J., Ouyang, L.Y., Cárdenas-Barrón, L.E., Goyal, S.K.: Optimal credit period and lot size for deteriorating items with expiration dates under two-level trade credit financing. Eur. J. Oper. Res. 237(3), 898-908 (2014) 